\title{
Optimal Scheduling of Hybrid Pumped Hydro Storage System using Linear Programming
}

\author{
B. Shyam, B. Harini Krishna, P. Kanakasabapathy
}

\begin{abstract}
This paper presents optimal scheduling of a gridconnected microgrid with grid, solar PV system, and wind energy system acting as sources and a local water reservoir actingas a storage system. Using mathematical models of solar PV, wind energy system, load profile, and pumped storage system, the optimization problem is formulated to minimize thedaily operating cost taking into account all the constraints. Using a modified linear programming algorithm based on varying price weight, an optimum schedule is obtained and the minimum operating cost is determined.Comparison of operating cost is carried out based on all possible combinations of available sources and storage system. Cases of maximum initial reservoir volume and minimum initial reservoir volume were considered for each combination of sources and storage system. Finally, by analyzing the simulation results and cost calculations, share of different renewable energy sources, grid, and storage system in meeting the load isobtained.
\end{abstract}

Index Terms--- Scheduling, Pumped Hydro Storage, Renewable Energy Sources, Solar PV, Wind Energy.

\section{INTRODUCTION}

India's energy sector has significantly grown over the last decades. It is the third largest consumer and 3rd largest producer of electricity. It is due to the rapid growth of the economy, increase in exports, developing infrastructure and increment in household income [1]. The shares of fossil fuels in the energy sector of India is $81.9 \%$ and the renewable share $15.3 \%$ [2]. Since three fourth of the electricity of Indiais produced by fossil fuel, particularly coal, there is a major im- pact on the environment and also the fossil fuels are depleting rapidly, which poses a major problem to the energy sector. Renewable energy resources provide a solution to this threat. Wind and Solar are the major renewable energy resources that are widely available in our country. It is the fourth largest wind power producer in the world with $49.3 \%$ contribution to the renewableenergyfieldwhereassolarcontributes $31.4 \%$.

[3] Though there is abundant availability of renewable energy resources in our country, the intermittent nature of the renewable energy resources poses a hitch in merging them with our existing power system [4]. The existing solution for the problem is the storage system [5]. The effect on the grid due to the fluctuating nature of renewable energy generation can be nullified by connecting energy storage

Revised Version Manuscript Received on August 19, 2019.

B. Shyam, Department of Electrical and Electronics Engineering, Amrita Vishwa Vidyapeetham, Amritapuri, India. (e-mail: shyamb@am.amrita.edu)

B. Harini Krishna, Department of Electrical and Electronics Engineering, Amrita Vishwa Vidyapeetham, Amritapuri, India. (e-mail: bukkapatnamharini@gmail.com)

P. Kanakasabapathy, Department of Electrical and Electronics Engineering, Amrita Vishwa Vidyapeetham, Amritapuri, India. (e-mail: sabapathy@am.amrita.edu) system between the RES and grid which act as a buffer between them[6].

Using pumped hydro storage along with available renewable energy resources, clean energy can be generated [7]. The fuel cost and emission can be reduced by using hydro-thermal co- ordinations. At peak hours the pumped hydro storage meets the load demand and at low peak hours, the water is pumped back to the upper reservoir. [8] In India, the plan ofintegrating pumped hydro storage with nuclear plant started in the 1970s. The country's first pumped hydro storage, Nagarjuna Sagar pumped hydro storage plant was commissioned in the year 1985 . Presently 11 pumped hydro plants are under operation and 56 new sites were identified as suitable for a pumped hydro scheme by CEA.[9]

In this paper, a modified linear programming method is used to obtain an optimal schedule for a hybrid pumped hydro storage system. The solar PV, wind and pumped hydro storage system are mathematically modelled. An objective functionis formulated for the systemandthedifferentconstrainsand boundaries of the system are identified. The system is simulated for different cases and a comparative study for various cases isdone.

\section{SYSTEMDESCRIPTION}

In the proposed system as shown in figure 1, the load is supplied by the available renewable energy resources and grid. The pumped hydro storage acts as either a load or an energy source based on the hour of operation and the volume of the upper reservoir. There is no power exported to the grid from renewable energy sources and pumped hydro storage.

Atoffpeakhours,ifthevolumeoftheupper reservoirs less than the maximum volume the pumped hydro storage will be in pumping mode and will act as a load. The grid and renew- able energy sources supply the load and pumped hydro storage. During peak hours, the operation of the grid is restricted. The pumped hydro storage acts as a source i.e. it will be in generating mode. The load demand is met by pumped hydro storage along with renewable energy sources. The renewable energy sources participate in meeting the demand only when they are available. During the availability of renewable energy sources, they are dedicated to the load. Based on the volumeof the upper reservoir, the excess renewable energy will be given to the pumped hydro storage. For a small scale, pumped hydro storage is not economical [10].

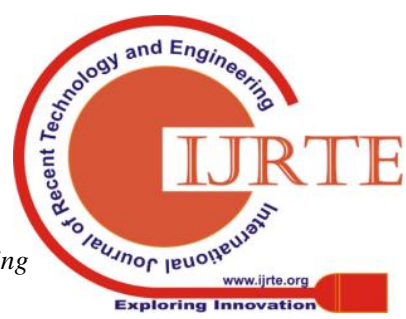


So, a locally available dam is used as upper reservoir and a nearby canal is used as the lower reservoir storage is not economical [10]. So, a locally available dam is used as upper reservoir and a nearby canal is used as the lower reservoir.

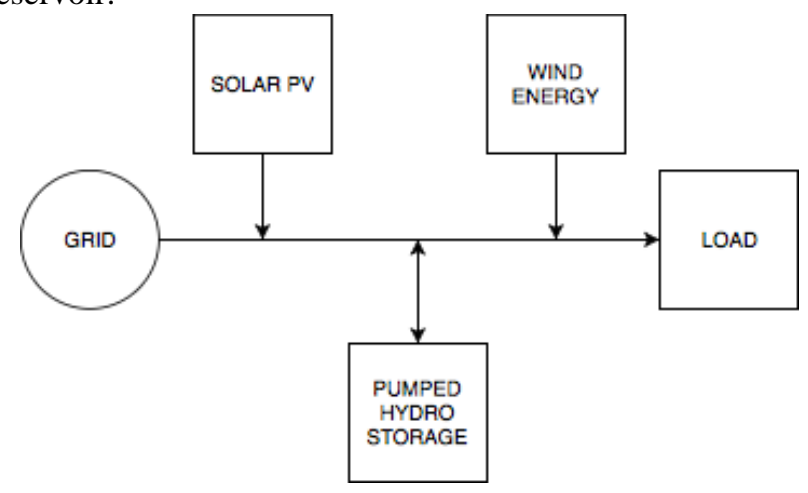

Fig. 1: Proposed System Block Diagram

\section{MODELLING}

Modelling of SolarPV

The solar PV can be calculated by knowing the area of the panel and the PV system efficiency.

$$
P(k W)=A \times \eta \times I
$$

where

- A: area of the PV array

- $\eta$ : Efficiency of the PV system

- I : Solar Irradiation

The solar irradiation data for a location can be collected and the output PV power can be calculated. [11].

\section{Modelling of Wind Power}

For a given rotor swept area the output power from the wind turbine can be calculated by

$$
P(k W)=k \times C \quad p \times \frac{1}{2} \times \rho \times A \times v^{3}
$$

where

- $C_{p}$ : Maximum powercoefficient

- A:Sweptareaoftherotor

- $V:$ WindVelocity

- $k$ :ConstanttoconvertpowerintoKW

- $\rho$ : Density ofair

Thewindturbinegivesanoutputpoweronlywhenthevelocity of the wind is between the cut-in and cut-out velocity. Theoutput power of the wind plant can be calculated by knowingthe wind velocity of the location. [12]

\section{Modelling of Pumped Hydro Storage}

The capacity of pumped hydro storage in the upper reservoircan be calculated as,

$$
P(W)=\frac{\rho \times V_{u} \times g \times h \times \eta}{t \times 3.6 \times 10^{6}}
$$

The power required to pump the water from the upper reservoir to the lower reservoir during the pumping mode is given by

$$
P(W V)=\frac{\rho \times g \times h \times Q_{p}}{\eta_{p} \times t}
$$

The power obtained by the pumped hydro storage during generating mode is given by [13]

$$
P(g W)=\frac{\rho \times g \times h \times \eta_{q} \times Q_{q}}{t}
$$

Where

- $\rho:$ Density ofwater

- $g$ : Gravitationalconstant

- $h$ : waterhead

- $Q_{p}$ : Water flow rate duringpumping

- $Q_{g}$ : Water flow rate duringgeneration

- $\eta_{p}$ : PumpingEfficiency

- $\eta_{g}$ : generatingefficiency

- $t$ : time period ofoperation

- $V_{u}$ : Volume of the upperreservoir

\section{Grid energy pricing}

The grid energy pricing depends on the time of usage. An approximate energy pricing for peak, standard and off-peak hour are assumed for different intervals of time as shown in the tableI.

Table I: Grid Energy Pricing

\begin{tabular}{|c|c|c|}
\hline T IME $(h)$ & Hour of usage & cost $/ \mathrm{kW}$ \\
\hline$(0,7) \cup(22,23)$ & Off-peak hour & $5 R s$ \\
\hline$(11,17) \cup(20,21)$ & Standard hour & $7.5 R s$ \\
\hline$(8,10) \cup(18,19)$ & Peak hour & $15 R s$ \\
\hline
\end{tabular}

\section{LoadCurve}

The daily load curve is shown in figure 2 [14]

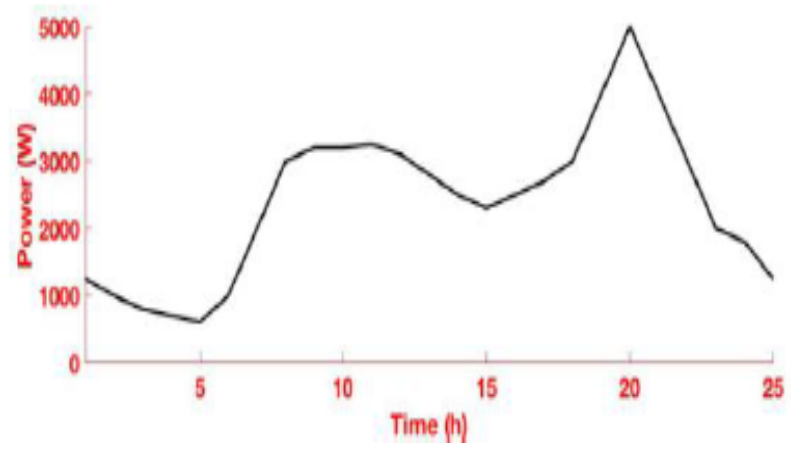

Fig. 2: Load Profile

\section{SolarData}

The PV profile shown in figure 3 is obtained collecting a locations irradiation data for each hour and calculating the output power of solar PV using equation 1.

\section{Wind Data}

The wind profile as shown in figure 4 is plotted by obtaining the wind velocity of a location on hourly basis. Usingequation 2 the power output for for different wind velocities iscalculated. 


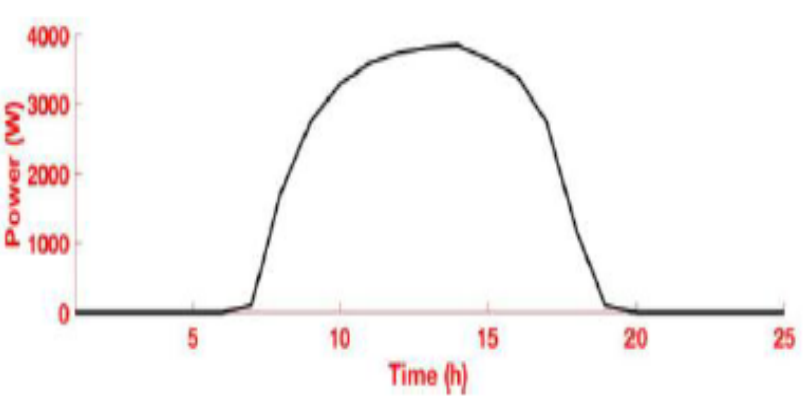

Fig. 3: Solar Data

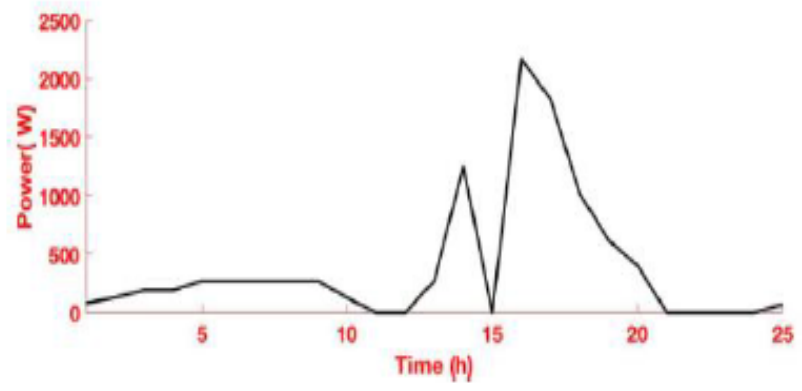

Fig. 4: Wind Data

\section{FORMULATION OF OPTIMIZATIONPROBLEM}

\section{Objective Function}

This work focuses mainly on the reduction of the usage of grid power. This can be written asMinimize,

$$
F=\sum_{j=1}^{n}\left(P_{g p h}+P_{g l}\right) \times R s \times \Delta t
$$

Thepowerfromthegridtotheloadorpumpedhydroshould be such that it should be minimal at any hour of the day.The minimization function is subjected to different constraints based on thesystem.

\section{VariableConstrains}

The instantaneous power from the wind farm to meet the load or pumped hydro storage interval i should not exceed the total power generated by wind farm at interval $\mathrm{i}$.

$$
P_{w p h(i)}+P_{w l(i)} \leq P_{w(i)}
$$

The sum of power drawn from Solar PV in any interval to meet the load or pumped hydro demand should be less than or equal to the total power generated by solar PV at the particular interval.

$$
P_{p v p h(i)}+P_{p v l(i)} \leq P_{p v(i)}
$$

The total allowable power that can be drawn from the grid at any interval should be equal to or greater than the sum of power drawn from the grid to meet the load or supply pumped hydrostorage.

$$
P_{p g l(i)}+P_{g p h(i)} \leq P_{g(i)}
$$

\section{EqualityConstrains}

The sum of power from renewable energy sources, storage unit, and the grid should be equal to the total load demand at any interval of time.

$$
P_{g l(i)}+P_{p v l(i)}+P_{w(i)}+P_{p h l(i)}=P_{l(i)}
$$

\section{Variable Boundaries}

The boundaries of the variable parameters of the system can be set by a lower and upper limit so that the parameter does not violate any of the constraints of the system. The limits are as givenbelow.

$$
0 \leq P_{g l(i)} \leq P_{g l \max }
$$

$$
\begin{gathered}
0 \leq P_{w(i)} \leq P_{w \max } \\
0 \leq P_{p h l(i)} \leq P_{\text {phlmax }} \\
V_{r \min } \leq V_{r(i)} \leq V_{\text {max }}
\end{gathered}
$$

where

• $\mathrm{i}: 1,2, . ., 24$

- Ppvph:PowerfromPVtoPHS

- Pwph:PowerfromWindfarmtoPHS

- Pwl:PowerfromWindfarmtoload

-Ppvl:PowerfromPVtoload

- Pgph:PowerfromgridtoPHS

- Pgl:Powerfromgridtoload

- Pphl:PowerfromPHStoload

- Vr: Volume of upper reservoir

- Rs: GridPricing

Modes of Pumped Hydro Storage

The pumped hydro storage acts in two modes of operation

1) Pumping Mode:When the hour is an off-peak houror if the renewable energy sources exceed the load demand, based on the volume of the reservoir the pumping action takes place. The amount of water available in the upper reservoir at anyinstantoftimeisgivenby

$$
V_{r(i)}=V_{r(i-1)}+\left(V_{p v p h(i)}+V_{g p h(i)}+V_{w p h(i)}\right)
$$

2) Generating Mode: if the hour is of peak hour and the renewable are not enough to meet the load, the pumped hydro storage acts as an energy source to meet the load. The status ofthewateravailabilityintheupperreservoirisgivenby

$$
V_{r(i)}=V_{r(i-1)}-\left(V_{p h l(i)}\right)
$$

The current volume of the upper reservoir at the end of any interval can be calculated by combining equations 15 and 16 , that is

$$
V_{r(i)}=V_{r(i-1)}+\left(\left(V_{p v p h(i)}+V_{g p h(i)}+V_{w p h(i)}\right) V_{p h l(i)}\right)
$$

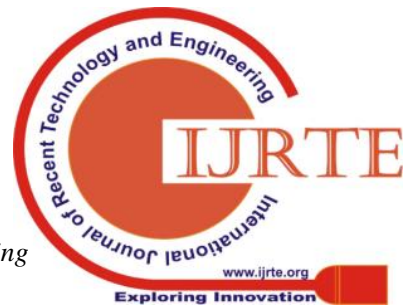


Where

- $\operatorname{Vr}(i-1)$ : Volume of reservoir at the end of previoushour

- Vpvph : Volume filled byPV

- Vgph : Volume filled bygrid

- Vwph : Volume filled by Windfarm

- Vphl:Decreaseinvolumeduringgeneratingmode

\section{Modified Linear Programming Algorithm}

Figure 5 represents an approach to optimizationusing modified linear programming. The data of load, power from solar PV and wind, the volume of the reservoir and the grid pricing is read and the present volume is checked. If the present volume is less than the maximum volume, the hourof operation is checked or else the default pumping and generating cost weightage is taken. If the hour of operation is an off-peak hour, the generating cost weightage is increased and the pumping cost weightage is reduced so that the pumping takes place and if it isnot an off-peak hour then pumpingcost weightage is increased and the generating cost weightage is reduced so that the pumping action does not take place at peak hours. The linear programming optimization is run for the defined condition. If all the constraints are satisfied the volume is updated. At the end of all iterations, a 24 hours schedule isprinted.

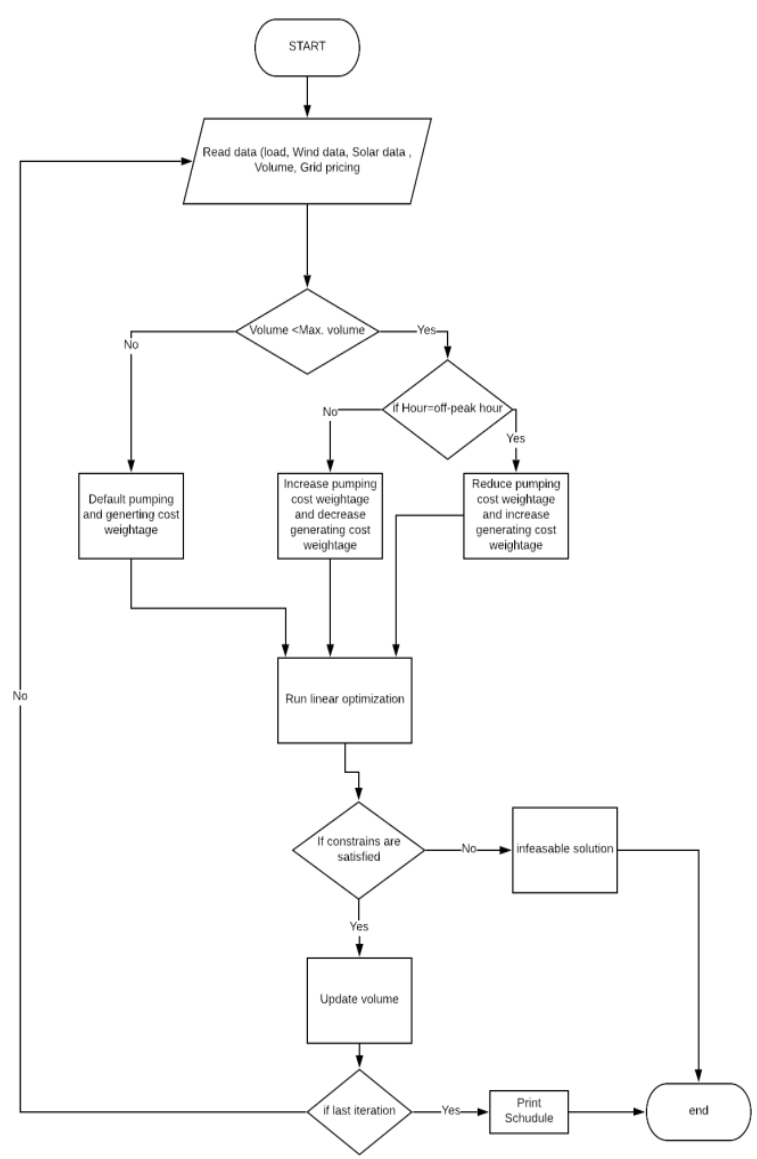

Fig. 5: Flow Chart of Proposed Method

The weightage parameters are introduced in the objective function. The equation 6 can be re-written asMinimize

$$
F=\sum_{j=1}^{n}\left(\left(W_{p} P_{g p h}+P_{g l}\right) \times R s \times \Delta t\right)+\left(\begin{array}{ll}
W_{g} P & p h l
\end{array}\right)
$$

Where Wprepresents the pumping cost weightage and $\mathrm{Wg}$ represents the generating cost weightage.

The objective function and the constraints of the system are solved using linear programming method in Matlab 2018b. Minimize f, st

$$
\begin{gathered}
A_{x} \leq b \\
A_{e q x}=b_{e q} \\
l b \leq x \leq u b
\end{gathered}
$$

where ' $f$ ' represents the objective function, equation 20 repre- sent the equality constraint parameters, equation 19 represent the inequality constraint parameters and equation 21 represent the lower and upper limits of the variables

The linear programming method can used using an inbuilt function as given below

$$
y=\operatorname{linprog}(f, A, b, A e q, b e q, l b, u b)
$$

At peak hour rating, based on the availability of the renewable energy sources, the use of pumped hydro will be maximum, avoiding the use of grid the cost of the power can be reduced. During the off-peak hour, the grid will be used to supply the load and some part of the pumped hydro plant.

\section{OPTIMAL SCHEDULING OF PROPOSEDSYSTEM\& RESULTS}

\section{Input Data and SystemSpecifications}

\begin{tabular}{|c|c|}
\hline Maximum Load & $5 \mathrm{~kW}$ \\
\hline \multicolumn{2}{|l|}{ Solar PV } \\
\hline PV rating & $4 \mathrm{~kW}$ \\
\hline Area & $22.22 \mathrm{~m}^{2}$ \\
\hline$\eta$ & $18 \%$ \\
\hline \multicolumn{2}{|c|}{ Wind Energy System } \\
\hline Wind turbine rating & $3.3 \mathrm{~kW}$ \\
\hline Swept area & 175 sq.m \\
\hline cut-in velocity & $6 \mathrm{~m} / \mathrm{sec}$ \\
\hline cut-out velocity & $18 \mathrm{~m} / \mathrm{sec}$ \\
\hline \multicolumn{2}{|c|}{ Pumped Hydro Storage } \\
\hline Volume of upper reservoir & $816 \mathrm{~m}^{3}$ \\
\hline Rate of charge & $0.009 \mathrm{~m}^{3} / \mathrm{sec}$ \\
\hline Rate of discharge & $0.11 \mathrm{~m}^{3} / \mathrm{sec}$ \\
\hline Height & $10 \mathrm{~m}$ \\
\hline
\end{tabular}

The load demand for 24 hours time period. The scheduling in this work is done for the load in figure 2 with an intervalof one hour for a day. The system parameters used in the simulationaregivenintableII.

Table II: System Specifications

Simulation Results andDiscussion

The simulation is carried out with minimum initial reservoir level. During the off-peak hours which is from $0^{\text {th }}$ to $7^{\text {th }}$ hour and $22^{\text {nd }}$ to $24^{\text {th }}$ hour the load is supplied by the grid. 
The grid also supplies during standard hours which are from $17^{\text {th }}$ to $18^{\text {th }}$ hour and $21^{\text {st }}$ to $22^{\text {nd }}$ hour where the renewable energy sources are not capable to handle the load. Figure 6 shows the participation of the grid to serve the load in a day.

The pumped hydro storage acts as a load on the grid only when there is an occurrence of the low peak hour. The figure 7 refers

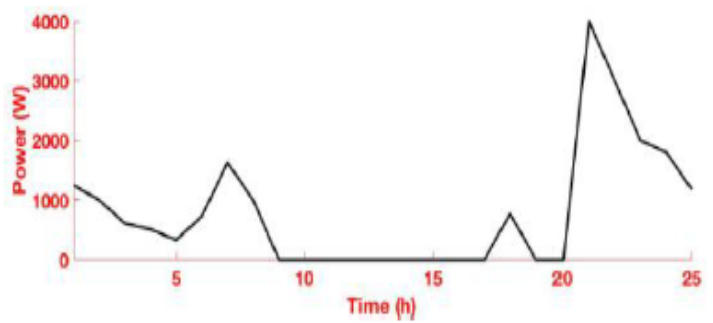

Fig. 6: Grid to Load

to the power drawn from the grid to supply the pumped hydro storage. During the off-peak period $1^{\text {st }}$ to $2^{\text {nd }}$ hour and $23^{\mathrm{rd}}$ to $24^{\text {th }}$ the grid power is utilized to fill the upper reservoir of pumped hydrostorage.

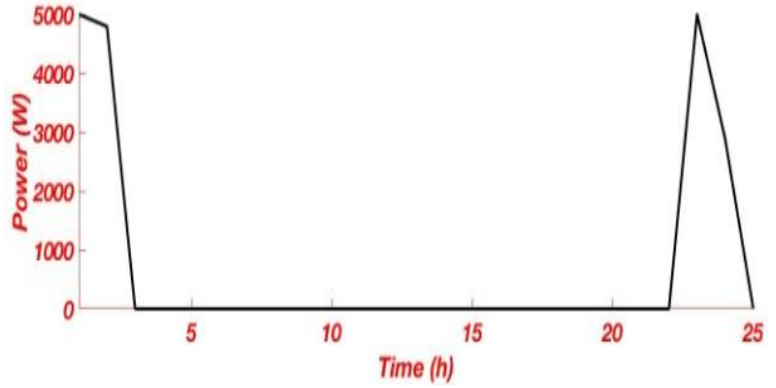

Fig. 7: Grid to PHS

When solar energy is available, the PV is dedicated to meet the load demand. if the PV is excess than load, based on the volume of the reservoir, the excess power is used to meet the demandofthepumpedhydrostorage.

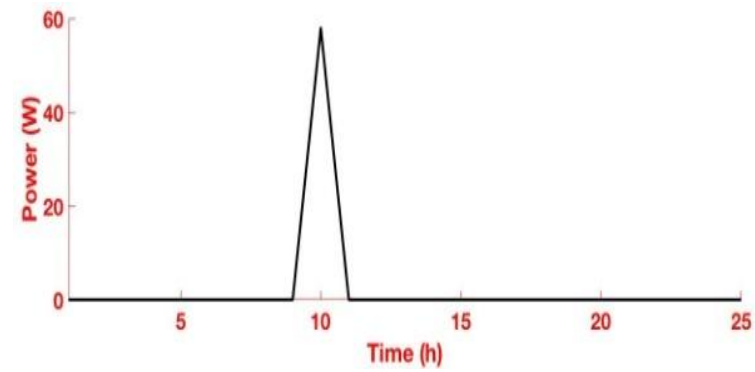

Fig. 8: PV toPHS

At $9^{\text {th }}$ to $10^{\text {th }}$ hour, the power from PV is excess to thatof load demand. Figure 8 shows that the excess power from Solar PV is given to pumped hydro storage. Figure 9 shows the participation of PV in the hybrid system to meet the load demand.

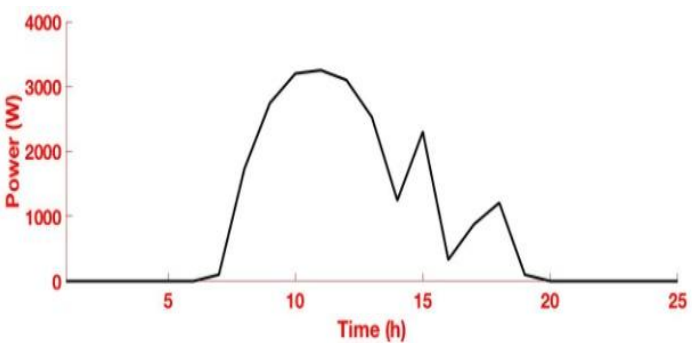

Fig. 9: PV to Load
At $1^{\text {st }}$ to $3^{\text {rd }}$ hour and $9^{\text {th }}$ to $10^{\text {th }}$ hour , the power from wind energy system is given to pumped hydro system. The figure10 shows the power flow profile from wind energy system

to pumpedhydrostorage. Whenwindenergyisavailable, windener gy system supports the other energy sources to meet the load. The figure 11 shows the role of wind energy system in meeting a part of the load in a day.

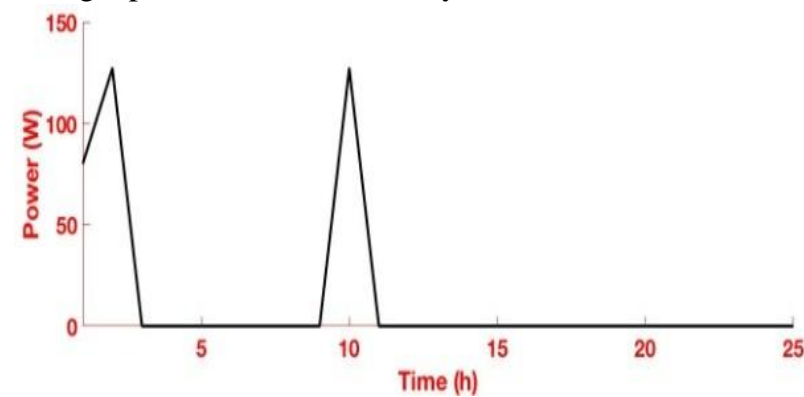

Fig. 10: Wind to PHS

The renewable energy sources supply the load at any hour of the day according to their availability. The pumped hydro storage acts as a source only when there is a peak hour which reduces the burden on the grid at peak hours. At $8^{\text {th }}$ to $9^{\text {th }}$ hour, the first peak hour of the day occurs. The available renewable energysourcesarenotenoughtomeettheload.

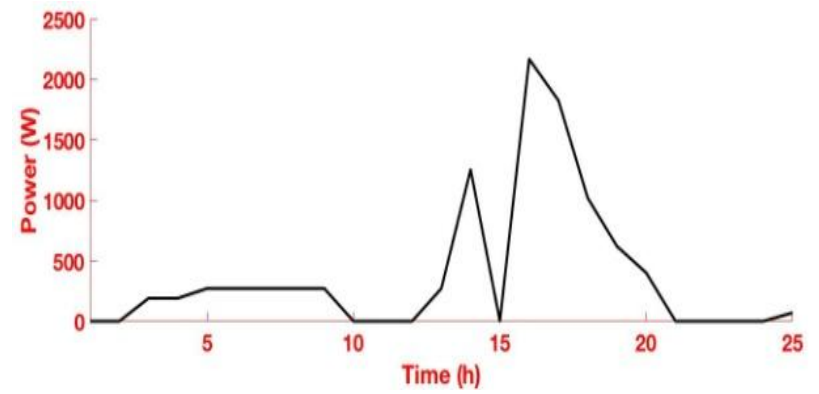

Fig. 11: Wind to Load

The pumped hydro storage supports the system to meet the demand at the first peak hour. During the peak hours at $19^{\text {th }}$ to

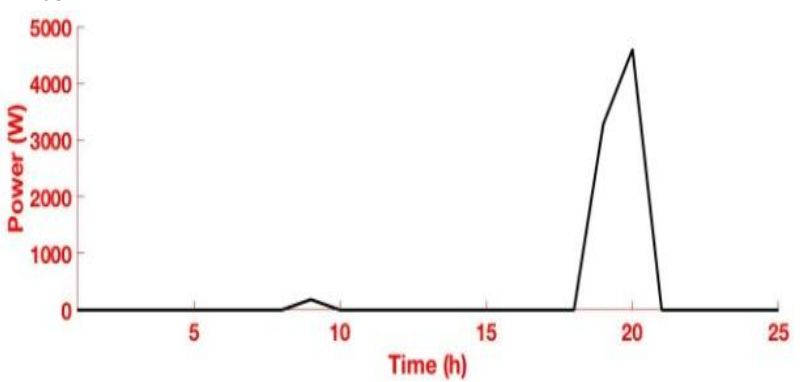

Fig. 12: PHS to Load

$20^{\text {th }}$ hour, the renewable energy sources are barely available. The major part of the load is supplied by the Pumped hydro storage during these hours. The figure 12 shows the amountof power drawn from pumped hydro storage to meet the load during peak hours. Due to the involvement of pumped hydro storage in the system, the burden on the grid is reduced atpeak hours and the operational cost of the grid is reduced. 
Thechangeinthevolumeofthereservoirisshowninfigure13. At peak hours, that is from $9^{\text {th }}$ to $10^{\text {th }}$ hour and $19^{\text {th }}$ to 21 hour the pumped hydro acts as a source, so the volume in the upper reservoir comes down and at off peak hours, $1^{\text {st }}$ to $3^{\text {rd }}$ hour and $23^{\text {rd }}$ to $24^{\text {th }}$ hour the pumped hydro acts as a load. It draws power from the other sources to pump the water back into the upper reservoir.

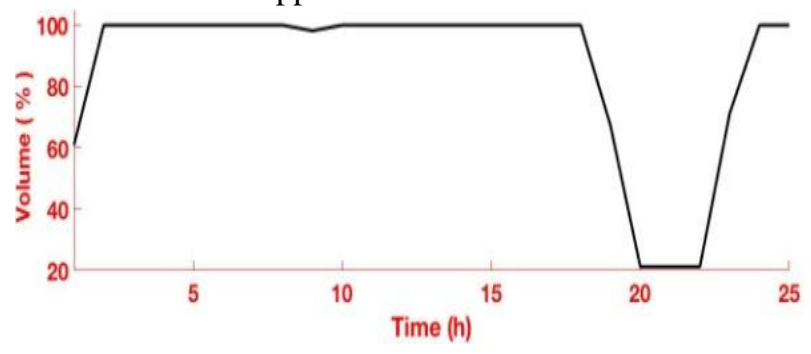

Fig. 13: Change in volume of upper reservoir

\section{SystemAnalysis}

The contribution of each energy sources in the absence and presence of pumped hydro storage to meet the total load in a day is shown in table III and IV respectively. It is observedthat the hybrid system with pumped hydro storage reduces the burdenonthegridbysharingtheloadwithPHS.

Table III: Participation of Energy Sources in Meeting the Load Demand without PHS

\begin{tabular}{|c|c|c|c|c|}
\hline \multirow{2}{*}{ Source } & \multicolumn{4}{|c|}{ System } \\
\cline { 2 - 5 } & Grid Alone & Grid +PV & Grid+Wind & Hybrid \\
\hline Grid & 59.950 Units & 31.717 Units & 50.520 Units & 27.588 Units \\
\hline PV & - & 28.233 Units & - & 28.182 Units \\
\hline Wind & - & - & 9.430 Units & 4.180 Units \\
\hline Load & \multicolumn{4}{|c|}{59.950 Units } \\
\hline
\end{tabular}

TableIV: Participation of Energy Sources in Meeting the Load DemandwithPHS

\begin{tabular}{|c|c|c|c|}
\hline \multirow{2}{*}{ Source } & \multicolumn{3}{|c|}{ System } \\
\cline { 2 - 4 } & Grid +PV & Grid+Wind & Hybrid \\
\hline Grid & 22.361 Units & 36.267 Units & 19.529 Units \\
\hline PV & 28.233 Units & - & 22.771 Units \\
\hline Wind & - & 9.701 Units & 8.076 Units \\
\hline PHS (as energy source) & 9.356 Units & 13.982 Units & 9.574 Units \\
\hline Load & \multicolumn{3}{|c|}{59.950 Units } \\
\hline
\end{tabular}

Table $\mathrm{V}$ shows the daily operational cost comparison for different systems. It can be observed that the initial reservoir volume plays a vital role in reducing the daily operational cost of the grid.

Table V: Cost Comparison

\begin{tabular}{|c|c|c|}
\hline \multicolumn{3}{|c|}{ Without Pumped Hydro storage } \\
\hline System & \multicolumn{2}{|l|}{ Cost (in Rs) } \\
\hline Grid Alone & \multicolumn{2}{|c|}{551} \\
\hline Grid + PV & \multicolumn{2}{|l|}{289} \\
\hline Grid + Wind & \multicolumn{2}{|l|}{471} \\
\hline Grid + PV + Wind & \multicolumn{2}{|l|}{281.07} \\
\hline \multicolumn{3}{|c|}{ With Pumped Hydro Storage } \\
\hline System & Reservoir initial volume & cost (in Rs) \\
\hline \multirow[t]{2}{*}{ Grid + PV } & Zero & 240 \\
\hline & Maximum & 190 \\
\hline \multirow[t]{2}{*}{ Grid + Wind } & Zero & 432 \\
\hline & Maximum & 383 \\
\hline \multirow[t]{2}{*}{ Hybrid } & Zero & 206 \\
\hline & Maximum & 156 \\
\hline
\end{tabular}

\section{CONCLUSION}

In this paper, a novel method to minimize the daily operational cost of a system is proposed. The system consists of a PV system and Wind system with pumped hydro storage. The total operational cost of the grid for a day is reduced using modified linear programming. From the obtained results, itcan be inferred that the pumped hydro storage plays a major role in supporting the system. Pumped hydro storage provide an effective integration between the renewable energy sources and the load. Due to the addition of pumped hydro storage the burden on the grid is reduced. The daily operational cost of the system is dependent on the initial volume of upper reservoir. The system can further be studied by accounting variouslosses associated to it and also the pumped hydro storage can be used as source during few standard hours.

\section{REFERENCES}

1. "Growth of Electricity Sector in India from 1947-2018" CEA Retrieved 20 August2018.[Online]

2. Availabe

http://www.cea.nic.in/reports/others/planning/pdm/growth2018.pdf

3. "BP Statistical Review of World Energy June 2018". Retrieved 26 August 2018.2 [Online], Available:https://www/bp.com/content/bp/businesssites/en/global/corpoprate/pdfs/ebergy-economics/statisticalreview/bp- stats-review-2018-full-report-pdf

4. " Physical Progress (Achievements)" Minestry of New andRenewableEnergy,Govt.ofIndia,Retrieved18July2018[Online]

5. Available:https://mnre.gov.in/physical-progress-achievements

6. Shyam and P. Kanakasabapathy, "Renewable energy utilization in India policies, opportunities and challenges," 2017 Internationa Conference on Technological Advancements in Power and Energy ( TAP Energy), Kollam, 2017, pp.1-6.

7. Z. Wang et al., "Research on the active power coordinationcontrol system for wind/photovoltaic/energy storage," 2017 IEEE Conference on Energy Internet and Energy System Integration (EI2), Beijing, 2017, pp.1-5

8. Shyam B,Kanakasabapathy P,'Large scale electrical energy storage systems in India- current status and future prospects," August 2018 JournalofEnergyStorage, Volume18,Pages 112-120

9. Valsan and P. Kanakasabapathy, "Design and implementation of smart energy management system for stand-alone micro-hydro systems," 2017 International Conference on Technological Advancements in Power and Energy(TAPEnergy),Kollam,2017,pp.1-6.

10. V. Valsan and P. Kanakasabapathy, "Smart energy management and control of stand-alone pico-hydro systems," 2017 Innovations in Power and Advanced Computing Technologies (i-PACT), Vellore, 2017, pp. 1-6.

11. Dr. P. Kanakasabapathy, Dynamic Self Scheduling of pumped storage power plant in Energy and Ancillary Service Markets Using Sliding Window Technique, World Academy of Science Engineering and Tech- nology, vol. 1,2014

12. Guilherme de Oliveira e Silva,Patrick Hendrick, "Pumped hydro energy storage in buildings,"Applied Energy, Volume 179, 1 October2016,Pages 1242-1250.

13. K. Kusakana, "Using PV with borehole pumped hydro storage systems for small farming activities in South Africa," 2017 IEEE Innovative

Asia),Auckland,2017,pp.1-6.

14. J. Jamii and F. Mimouni, "Model of wind turbine-pumped storage hydro plant," 2018 9th International Renewable Energy Congress (IREC), Hammamet, 2018, pp.1-6.

15. Nobile, G. Sari and A. Schwery, "Variable Speed Hydro Pumped Storage as Flexible Enabler of Intermittent Renewable Penetration,' 2018 IEEE Power Energy Society General Meeting (PESGM), Portland, OR, 2018, pp.1-5.

16. K. Gaur, H. Kumar, R.P.K. Agarwal, K.V.S. Baba and S.K. Soonee "Analysing the electricity demand pattern," 2016 National Power SystemsConference(NPSC),Bhubaneswar,2016,pp.1-6

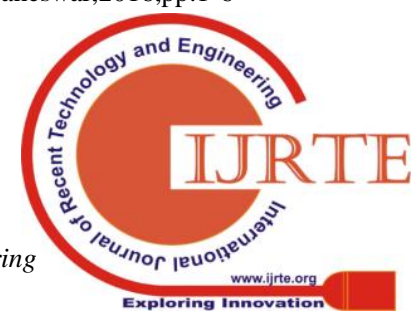

